\title{
CREATION OF SPECIAL CONDITIONS TO LEARN SCIENCE FOR THE DEAF AND HARD - OF- HEARING STUDENTS IN INCLUSIVE PROGRAMS AT TECHNICAL UNIVERSITY
}

\author{
Oreshkina O.A., Gourov A.A. \\ Department of Chemistry, Federal State Budgetary Educational Institution of Higher Education \\ "Bauman Moscow State Technical University (National Research University)", Moscow, \\ e-mail: Olga_Oreshkina@yahoo.com
}

\begin{abstract}
Adaptive, organization and technology solutions have been designed and implemented at Bauman Moscow state technical university to raise efficiency in mastering chemistry of those deaf and hard-of hearing students who study chemistry in the inclusive programmes. Key solution is an introduction of the special adaptive accompanying chemistry course named "Cognitive technologies to accompany basic discipline of Chemistry" which is being taught side-by-side with the main "Chemistry" course. Such a combination of two teachers' efforts within teaching chemistry deaf and hard-of hearing students is being considered as a "cooperative teaching". As major focus of the adaptive course authors consider actualizing basic knowledge in chemistry of deaf and hard-of hearing students applied to studied materials in the main chemistry course as well as identifying their individual cognitive difficulties while study chemistry and their overcoming through forming cognitive general cultural and special competences. Teaching adaptive chemistry course in specialized multimedia classrooms with use state-of-the art information and communication technology, demonstrating and clarifying chemical experiments during classes, preparing training materials based on peculiarities of students as well as doing students' research works contribute to the development of these competencies in the deaf and hard-of hearing students and their better understanding the "Chemistry" content semantic. In this way, teachers are able to explore and use opportunities for multimodal instruction. Success indicators of hearing impaired students in chemistry are given before and after the introduction of the adaptive course in their educational process.
\end{abstract}

Keywords: deaf and hard-of hearing students, inclusion, special education conditions, accompanying, adaptive technological course, multimodal instruction

Employees to fill jobs in the areas of science, technology, engineering and mathematics (hereinafter -STEM) currently are in high demand nationwide and worldwide. However, many of the available jobs are going unfilled due to the lack of individuals trained to work in those fields. Research indicates [1] that particularly deaf and hard-of hearing people are underrepresented in the STEM workforce, and comprise an untapped pool workers for these STEM positions. To better prepare deaf and hard-of hearing students to excel and find jobs in STEM after graduation special conditions have to be created at education institutions.

"Plan of measures on the implementation in the regions of the Russian Federation of programs for accompanying young people with disabilities while receiving vocational education and promoting subsequent employment (Decree of the Russian Federation Government from July 16, 2016 No. 1507-p)" points out "inclusive vocational education and creation of special conditions" at institutions of vocation education, including technical universities.

University students with a disability [2] are young persons aged 18 to 35 with an impairments causing persistent disorganization of the body due to diseases, as a consequence of injuries or defects that led to limitation of his/her basic life categories [3], including learning and communication abilities.
As a result of these impairments, students with health limitations [4] including ones with a disability have special educational needs, which require an individual approach to each student in all educational disciplines, including "Chemistry".

Chemistry is a central science, and the study of chemistry is a gateway to a whole range of careers in the sciences and engineering professions. Non-accommodation in chemistry classes would foreclose a large range of career options to people with disabilities, including deaf and hard-of- hearing people.

Unfortunately, in the absence of special conditions, non-accommodation in chemistry classes at secondary schools school leavers with hearing impairments demonstrate extremely low level of knowledge in basic chemistry. This is being confirmed by the results of annual testing basic knowledge in chemistry in those deaf and hard-of- hearing students at Moscow state technical university named after N.E. Bauman (hereinafter - BMSTU), who are beginning to study chemistry at university. Test results of this category of students in 5 school years period (2013-2018 school years) are given in Table 1.

The test results of the deaf and hard-of hearing students are much lower than the results of ordinary BMSTU students in similar tests [5] and show almost full absence 
of basic knowledge in chemistry in this category of students, - especially among inclusive schools' leavers.

The objective is to create special conditions (by different accommodations) to learn chemistry for those deaf and hard-of- hearing BMSTU students who study in the inclusive programmes and to raise by this their effectiveness in mastering chemistry to the level of ordinary students.

At BMSTU students who are the deaf and hard - of - hearing are trained in adapted (inclusive) basic professional education programs (hereinafter - ABPEP) of baccalaureate. Training in the ABPEP lasts five years - one year more than training in bachelor programs for ordinary (able-bodied) students.

As research data "Academic Performance Indexes" (APIs) in Chemistry of those deaf and hard-of- hearing BMSTU students who have learned basics of Chemistry in 2011-2018 years within ABPEP have been used. As a method of research comparative analysis of students' APIs in periods of time before the introduction of accompanying adaptive course (2011-2013 years) and after its introduction (2013-2018 years) has been used.

An analysis of the deaf and hard-of-hearing students' problems while studying chemis- try confirmed that main their difficulties are the same as in ordinary students and are connected with their school experience in chemistry [6] in the absence of special conditions and features of the semantics of the discipline "Chemistry."

Meanwhile, common problems for all students studying chemistry deepen for students with hearing impairment as they are exacerbated by their individual features and limitations due to their hearing loss [7], including weak forming of cognitive skills. In this connection, they need to be accompanied in the process of studying chemistry at the technical university.

The number of the deaf and hard-of-hearing students who study chemistry is about $0.1 \%$ of the total number of ordinary BMSTU students studying this discipline. They study chemistry on the same program as ordinary students. To master this program hearing impaired need one semester more than able-bodied students who have only one semester. Lectures and seminars in "Chemistry" are being held in the specialized multimedia classes where lecturer use education materials in digital format. Lectures are being supported by interpreting. These ways to accommodate the education process in science disciplines for ABPEP students have been undertaken at BMSTU since the beginning of 2000-th.

Test results of the deaf and hard-of-hearing BMSTU students in basic course

Table 1 of chemistry in the period 2013-2018.

\begin{tabular}{|l|c|c|c|c|c|}
\hline \multirow{2}{*}{$\begin{array}{c}\text { Themes of the school chemistry } \\
\text { course essential for studying chem- } \\
\text { istry at technical university }\end{array}$} & \multicolumn{5}{|c|}{ Amount of unsatisfactory answers (\%) of the deaf and hard-of-hearing } \\
\cline { 2 - 6 } & \multicolumn{5}{|c|}{ BMSTU students to test tasks } \\
\cline { 2 - 6 } & $2013-2014$ & $2014-2015$ & $2015-2016$ & $2016-2017$ & $2017-2018$ \\
\hline $\begin{array}{l}\text { Chemical formulas and compounds' } \\
\text { names }\end{array}$ & 60 & 75 & 90 & 90 & 93,75 \\
\hline $\begin{array}{l}\text { Calculation of the amount of a sub- } \\
\text { stance based on Avogadro's law }\end{array}$ & 60 & 75 & 80 & 90 & 100 \\
\hline $\begin{array}{l}\text { Determining the degrees of oxida- } \\
\text { tion of atoms of a given element in } \\
\text { chemical compounds }\end{array}$ & 60 & 75 & 80 & 93 & 93,75 \\
\hline $\begin{array}{l}\text { Equations of electrolytic dissocia- } \\
\text { tion of salts with pointing out of cati- } \\
\text { ons and anions }\end{array}$ & 80 & 80 & 100 & 100 & 100 \\
\hline $\begin{array}{l}\text { C equations of chemical reactions } \\
\text { using the electronic balance method, } \\
\text { indicating the oxidant and reducing } \\
\text { agent }\end{array}$ & 90 & 90 & 100 & 100 & 93,75 \\
\hline $\begin{array}{l}\text { Tasks based on calculation of ex- } \\
\text { cess or deficiency of reagents }\end{array}$ & 90 & 100 & 100 & 100 & 100 \\
\hline
\end{tabular}


But there are some essential problems. Interpreters in chemistry lectures ideally should have an appropriate knowledge of the subject material and experience in converting scientific terms into signs. Interpreters with adequate knowledge of chemistry hardly can be found on the higher technical school level. It is impossible to find interpreters who are familiar with advanced chemistry concepts and terminology for the undergraduate and graduate student. Teachers should be aware that most scientific (chemical) terms have no specific counterparts in sign language. That is especially common in new or rapidly evolving scientific fields including those in chemistry, in which terms are constantly being coined. In these situations, the interpreter usually use finger-spelling words, thus slowing down his/her pace and losing teacher's information.

Those deaf students who orient on sign language should be able to recognize signs and gestures, interpret them into Russian and rapidly make their notes, that is they should be familiar in advance with meanings all those gestures that interpreters use to express specific chemical terms and concepts. Otherwise they lose a lot of needed information. Thus using sign language in science subject matters at state-of-the art-technical universities is nonsense.

Another essential problem is following. The program of discipline "Chemistry" for the deaf and hard-of- hearing students is being developed and implemented by assigned teacher of the department "Chemistry", who usually does not have special knowledge in the field of problems connected with hearing impairment as well as psycho-physiological characteristics of this specific category of students and can not appropriately work with each student. So, the abovementioned accommodations in teaching "Chemistry" for the deaf and hard-of-hearing students were not admitted enough.

Students often must coordinate multiple tasks at the same time: speech reading the instructor's spoken words or watching the interpreter while simultaneously taking notes; reading written material on overheads or whiteboards; or watching demonstrations, video. A potential problem arises because many students who are deaf receive and process only visual information from one source, instead of visual information supplemented by auditory cues.

The teacher's responsibility is to teach deaf and hard-of hearing students effectively doing appropriate accommodations. The purpose of accommodations is to provide equity of access and a level playing field for each student, regardless of his or her disability.
With this background a special adaptive chemistry course has been developed and implemented at BMSTU to accompany and support hearing impaired students in studying "Chemistry". The adaptive course named "Cognitive technologies to accompany basic discipline of Chemistry" (hereinafter "CTABD Chemistry") is intended only for those students with disabilities who study in ABPEP. This course is included in the category of compulsory BMSTU disciplines to be mastered by this specific students' contingent.

The introduction of "CTABD Chemistry" in the process of teaching/learning chemistry for the deaf and hard-of-hearing students is being considered as its important accommodation.

The "CTABD Chemistry" course is based on the "Chemistry" content. The main objectives of the "CTABD Chemistry" course are:

- actualizing basic knowledge of hearing impaired students applied to studied materials in the chemistry course;

- identifying individual cognitive difficulties in students who study chemistry and overcoming them through the formation of cognitive general cultural and special competences [7], which ensure a reduction in labor intensity and an increase in the efficiency in the study of "Chemistry" (and other natural sciences as well).

In this regard, another important feature of "CTABD Chemistry" course is that it is being developed and implemented by those teacher of the "Chemistry" department who does have special knowledge in the field of hearing loss, psychophysiological characteristics of students with hearing impairment and experience of longstanding work with this category of students.

The modular adaptive program of "CTABD Chemistry" course is being corresponded in content and structurally to the program of the "Chemistry" course. The key feature of "CTABD Chemistry" is its cognitive and technological component: the educational material in "Chemistry" is being clarified and mastered in the classes of "CTABD Chemistry" using following cognitive technologies [8]:

- expanding vocabulary and forming definitions in the thematic areas of chemistry (glossary technology);

- converting chemical information from one representative form to another;

- information and communication technologies (hereinafter - ICT) to search and analyze relevant chemical information;

- forming operational (logical-algorithmic) thinking and working with information, including ICT and others. 
Thus, accompaniment of students with disabilities (deaf and hard-of-hearing) in studying chemistry by special adaptive course is being considered as program-technological accommodation.

The organizational accommodation in teaching Chemistry for the deaf and hard-ofhearing students at BMSTU is providing parallel (side-by side) chemistry classes on two programs, namely: the main "Chemistry" program and the adaptive "CTABD Chemistry" program. To increase the effectiveness of studying "Chemistry", teachers attend each other's classes to monitor students' work, their difficulties and progress. Then they discuss and adjust the content of their classes. Such a combination of efforts of two teachers in the inclusive educational process in chemistry for the deaf and hard-of-hearing students can be considered as a "cooperative teaching (co-teaching)". Different models of "co-teaching" within inclusive education are given in [9]. The guarantee of effective cooperation of these teachers is knowing one of them problems of hearing loss; understanding individual features and difficulties of students with hearing impairments and finding ways to solve them within their courses.

The diversity of student's needs requires customizing accommodations for each student.

For this reason, teachers can explore opportunities for multimodal instruction. Using different methods of imparting information accommodates different styles of perception information.

In this connection education environment's accommodation is the important way of creation of special conditions. Lectures and seminars on "CTABD Chemistry" are being conducted in specialized multimedia classrooms, where teachers have access to a wide variety of multimedia ICT. ICT, including smart-board and document camera's technologies, speechinto -text technologies, Internet technologies and information office technologies are being considered as an important factor in cognitive learning. They provide visualization of verbal information; help to search, process, interpret information, make a glossary, form algorithms and structures of chemical experiments and processes, etc., activating the cognitive activity in students [10]. In this way, they form cognitive information competences in students, contributing to their better understanding the semantics of "Chemistry" subject matter.

The teacher of "CTABD Chemistry" prepares and provides training materials for students as well as individual student tasks, in electronic format, taking into account peculiarities of student's perception of information and his/her reading skills. The teacher use different interactive forms to work with students in the classes, including viewing and discussing video materials, demonstrating and analyzing chemical experiments, problem solving, ets., to involve them and to raise their cognitive activity. Thus, ICT support both students and teachers.

Demonstration of chemical qualitative and quantitative experiments during classes is another important feature of the "CTABD Chemistry". Experiments give students a clear idea of the chemical processes. They help students to make a connection between real substances and chemical signs, come to understanding methods of composing formulas and equations and thus to overcome the psychological barrier while transition from the empirical level of cognition to the theoretical one.

Laboratory research experience, a fundamental part of many scientific disciplines, is especially important for experimental sciences like chemistry. Most deaf and hard-of hearing students can work safely and effectively in the laboratory doing teacher-led research work if they understand its purpose and tasks, orient in it and are motivated to do it. Research students' work is a kind of accommodation of education process in Chemistry through "CTABD Chemistry" course. Deaf and hard-of-hearing students participate in developing chemical demo experiments within topics of "Chemistry". They compose equations of appropriate oxidation-reduction reactions as well as thermodynamics equations thus currying out a "full and thorough" examination of chemical process.

Indicators of progress in Chemistry of hearing impaired students before and after the introduction of "CTABD Chemistry" course, $\%$

Table 2

\begin{tabular}{|c|c|c|c|c|c|c|c|}
\hline School year & $2011-2012$ & $2012-2013$ & $2013-2014$ & $2014-2015$ & $2015-2016$ & $2016-2017$ & $2017-2018$ \\
\hline $\begin{array}{c}\text { APIs in Chem- } \\
\text { istry of the deaf } \\
\text { and hard-of hear- } \\
\text { ing students, } \%\end{array}$ & 70,2 & 80,1 & 100 & 100 & 91,7 & 93,3 & 96 \\
\hline
\end{tabular}


Usually hearing impaired students are very friendly with modern mobile gadgets. They are able to provide qualitative video materials of chemical experiments, to make needed calculations and to develop multimedia presentations which are being considered as education tools of a high demonstrativeness.

The evaluation of the deaf and hardof hearing students' success in mastering Chemistry is being based on their tests' results throughout the semester and intermediate credit or examination in the end of semester. Students who are deaf or hard-ofhearing generally can take the same written examinations basing on the same approaches as ordinary students take [11]. To understand oral instructions, however, they will require the same accommodations used during regular classroom sessions. Teachers should be aware that written tests may not be the most equitable way of evaluating students who became deaf very early in life, before acquiring language skills. Students who became deaf before learning to speak often have difficulty expressing themselves, which is largely due to the difficulty in learning to read and write a language they have never heard. Russian language is a second language for some deaf students. So, students' level of learning cannot always be measured by their ability to read and express themselves in written Russian. Therefore, when grading tests, teacher's care must be taken to distinguish the student's grasp of the subject matter from deficiencies in written Russian language skills.

APIs in Chemistry of the deaf and hard-of hearing students confirm raising the efficiency in learning Chemistry by these students with use above mentioned accommodations based on "CTABD Chemistry" course. Indicators of progress in Chemistry of hearing impaired students before and after the introduction of "CTABD Chemistry" course are given in Table 2.

\section{Conclusions}

Accompanying the deaf and hard-ofhearing BMSTU students who study "Chemistry" within ABPEP by parallel adaptive "CTABD Chemistry" course raises their efficiency in learning chemistry on average by twenty percent.

The "CTABD Chemistry" course focuses on individualized support of the deaf and hard-of-hearing students while learning chemistry. So it must be developed and implemented with participation of those teacher or specialist who understand students' problems connected with hearing loss as well as their psycho-physiological peculiarities and takes them into account planning his/her classes.

The cognitive-technology component of the "CTABD Chemistry" course requires multiple accommodations in the education process to provide better understanding of Chemistry content in the deaf and hard-ofhearing students and reduce their labor input while mastering chemistry.

Teaching "CTABD Chemistry" course in specialized multimedia classrooms with use a wide set of ICT, demonstrating chemical experiments during classes, laboratory learning experiences as well as carrying out teacher-led research students' work are being considered as creation of special conditions (accommodations) for multimodal cognitive instruction. Using different methods of imparting information accommodates different ways of information perception in students with hearing loss.

Deaf and hard-of hearing students must be in an environment that provides full access to the educational experience available to their able-bodied peers. The main goal of their education process is not just "inclusion" but "full participation". The adaptive technology course "CTABD Chemistry" through different accommodations ensures forming cognitive cultural and specific competencies in hearing impaired students, thus leveling their possibilities in educational and professional activities with those in ordinary people. Attention to individual needs can ensure that students with health limitations including those with disabilities participate fully in the education process.

\section{References}

1. Kathy A. Johncox "New partnership expands access to STEM careers". NTID Focus. National Technical Institute for the Deaf, Rochester Institute of technology. Fall/winter 2017. - P. 5.

2. Federal Law of 24.11.1951 N 181-FZ (amended on 29.12.2015) "On the Social Protection of Persons with Disabilities in the Russian Federation", Article 1.

3. Order of the Ministry of Labor of Russia No. 664n dating 29.09.2014. "On the approval of classifications and criteria used in the implementing MSE of citizens by federal state institutions of medical and social expertise".

4. Federal Law No. 273-FZ of 29.12.2012 (amended on 03.07.2016) "On Education in the Russian Federation", art.2.sec.16.

5. Fadeev G.N. Need for a new paradigm of school chemistry education. "Chemistry", №17, 2009. Electronic resource. Access mode: http://him.1 september.ru/view_article. php?ID=200901701 (date of the addressing: 08.01.2017).

6. Fadeev G.N., Karpov G.M. "Problems of teaching students who had not studied chemistry in 10-11 classes". Collection 
of scientific works of 64-th All-Russia scientific and practice conference with foreign participation "Actual problems of chemical and ecological education.” April, 13-15, 2017, RSPU named after A.I. Herzen, S-Petersburg, publication of Herzen RSPU, 2017. - P. 209-2012

7. Oreshkina O.A., Stanevsky A.G. Tutoring as an educational - rehabilitation technology for supporting programs of integrated vocational education for students with hearing impairment at BMSTU. Education through science. Col. reports of the International Symposium. - Moscow: BMSTU. 2006. - P. 81-82.

8. Oreshkina O.A. Support for students with disabilities in the development of natural science disciplines at technical university in the inclusion program. Science and education. $-\mathrm{M}$. BMSTU. El. No. 7, 2016. P.315-325. Access mode: http://tech- nomag.edu.ru/jour/article/view/1012 (date of the addressing: 23.03.2018)

9. Shumway L.K., Gallo G., Dickson S. \& Gibbs J. CoTeaching Handbook: Utah Guidelines. Utah State Office of Education, Salt Lake City, Utah, 2011.

10. Oreshkina O.A. Information and cognitive technologies supporting hearing impaired students in studying science disciplines at technical university in the inclusion. Materials of the XXVIII International Conference "Modern Information Technologies in Education". The Baitik Foundation, ITO-TroitskMoscow, June 17, 2017. - P. 494-496.

11. Regulations on the current monitoring of the progress and intermediate certification of students at BMSTU. Adopted by the Academic Council of BMSTU 08.02.2016. Moscow, 2016. 